\title{
Assessment of heart rate variability during different propofol effect site concentrations in patients with supratentorial tumours: A pilot study
}

\author{
Mohit Mittal, Radhakrishnan Muthuchellappan', GS Umamaheswara Rao1, \\ K. Kavyashree ${ }^{1}$, K. Vishnuprasad ${ }^{1}$
}

\begin{abstract}
Background: Impaired autonomic function (AF) can result in adverse cardiovascular events during the perioperative period. Literature suggests that patients with intracranial space-occupying lesions experience impaired AF depending on the site of tumour and associated raised intracranial pressure (ICP). The complex interaction between general anaesthetics, AF and intracranial tumours with raised ICP has not been extensively studied. Objective: This study was aimed at evaluating the cardiac AF (in terms of heart rate variability [HRV]) in patients undergoing surgery for supratentorial tumours, at baseline and at different propofol effect site concentrations $(\mathrm{Ce})$ during anaesthetic induction and the results were compared with patients undergoing non-cranial surgeries. Materials and Methods: In this prospective observational study, consecutive adult patients undergoing surgeries for supratentorial tumour (study group) and brachial plexus injury (control group) were recruited. Electrocardiogram was recorded for $5 \mathrm{~min}$ at three time points - before propofol induction, at propofol Ce $2 \mu \mathrm{g} / \mathrm{ml}$ and at Ce $4 \mu \mathrm{g} / \mathrm{ml}$. Results: Forty-five patients were recruited, 24 in study group and $2 \mathrm{l}$ in control group. In spite of similar baseline heart rate and blood pressure, low frequency (LF), high frequency (HF) and total power were significantly higher in control group. Baseline LF/HF, though higher in patients with intracranial tumour (craniotomy: $2.2 \pm 2.2$, control: $1.2 \pm 1.1$ ), was not significantly different between the two groups $(P=0.197)$. HRV variables in both the groups changed the same way in response to the increasing propofol Ce. Conclusion: HRV measurements were significantly different at baseline between the two groups. Following propofol administration, haemodynamic changes and HRV changes were similar in both the groups and also between the two groups.
\end{abstract}

Key words: Autonomic nervous system, heart rate variability, intracranial pressure, propofol, target controlled infusion

Department of Anaesthesia, Fortis Hospital, Mohali, Punjab, ${ }^{1}$ Department of Neuroanaesthesia, National Institute of Mental Health and Neurosciences, Bengaluru, Karnataka, India

Address for correspondence:

Dr. Radhakrishnan Muthuchellappan, Neurosciences Faculty

Centre, III ${ }^{\text {rd }}$ Floor, National Institute of Mental Health and

Neurosciences, Hosur Road, Bengaluru - 560 029, Karnataka, India.

E-mail: mrks1974@gmail.com

\begin{tabular}{|l|l|}
\hline \multicolumn{2}{|c|}{ Access this article online } \\
\hline Quick Response Code: & Website: \\
\hline & www.jnaccjournal.org \\
\cline { 2 - 2 } & \\
\hline & \\
\hline
\end{tabular}

\section{INTRODUCTION}

The factors controlling the tissue perfusion, namely, cardiac output, microcirculation and vascular tone, are modulated by the autonomic nervous system (ANS). ${ }^{[1]}$ Impaired ANS function can result in adverse cardiovascular events during the perioperative

This is an open access article distributed under the terms of the Creative Commons Attribution-NonCommercial-ShareAlike 3.0 License, which allows others to remix, tweak, and build upon the work non-commercially, as long as the author is credited and the new creations are licensed under the identical terms.

For reprints contact: reprints@medknow.com

How to cite this article: Mittal M, Muthuchellappan R, Rao GU, Kavyashree K, Vishnuprasad K. Assessment of heart rate variability during different propofol effect site concentrations in patients with supratentorial tumours: A pilot study. J Neuroanaesthesiol Crit Care 2017;4:108-13. 
period, especially during induction of anaesthesia, patient positioning, episodes of blood loss and surgical stimulation. These adverse events can result in tissue hypoperfusion. The haemodynamic changes that ensue following administration of anaesthetic drugs and mechanical ventilation may get exaggerated in patients who have pre-existing ANS dysfunction. Hence, assessment of ANS function in the pre-operative period is of immense help in identifying patients who may require strict haemodynamic vigilance in the perioperative period. $^{[2]}$

Cardiac autonomic modulation can be studied by measuring the heart rate variability (HRV) ${ }^{[3]}$ It is simple, non-invasive, can be performed at the bedside and is widely used in the clinical setting. HRV measurements have been used to predict hypotension in patients receiving spinal anaesthesia. ${ }^{[4]}$ Based on HRV measurements, propofol has been found to reduce cardiac parasympathetic tone. ${ }^{[5]}$

Patients with lesions in the frontal lobe and in septum pellucidum experience ANS dysfunction. ${ }^{[6,7]}$ Raised intracranial pressure (ICP) is associated with marked autonomic dysfunction and low HRV, and these changes precede the actual rise in ICP. ${ }^{[8,9]}$ Altered autonomic function (AF) caused by intracranial pathology may affect blood pressure regulation and thus pose a risk to cerebral perfusion, especially in patients who have impaired autoregulation. ${ }^{[10,11]}$

The complex interaction between general anaesthetics, ANS and intracranial tumours with raised ICP has not been extensively studied. Hence, in this study, we evaluated the cardiac AF (HRV) in patients undergoing surgery for supratentorial tumours at baseline and at different effect site concentrations (Ce) of propofol during anaesthetic induction and compared the results with those in patients undergoing non-cranial surgeries.

\section{MATERIALS AND METHODS}

This prospective observational study was conducted after Institute Ethics Committee approval and written informed consent from the patients. A total of 45 patients were recruited into the study. This study sample consisted of consecutive patients undergoing supratentorial tumour surgery (study group) and another set of consecutive patients undergoing intercosto-musculotaneous neurotisation for brachial plexus injury (control group). Adult patients of either sex aged between 20 and 50 years and belonging to American Society of Anesthesiologists Grade I and II were included in this study. Patients on $\alpha$ blockers, $\beta$ blockers, calcium channel antagonists, clonidine and angiotensin-converting enzyme inhibitors and with a history of cardiac disease and diabetes mellitus were excluded from the study.

No sedative and anticholinergic premedications were administered on the day of surgery. All patients received the morning doses of other medication as required including the antiepileptic medication. In the operating room, the patients were monitored with electrocardiogram (ECG), non-invasive blood pressure (NIBP), pulse oximetry and capnography. Baseline heart rate, NIBP and respiratory rate were recorded. ECG waveform for the study purpose was recorded using four chest leads connected to the PPVPM $^{\circledast}$ (Portable Handheld Vital Parameter Monitor) (Maestros Electronics and Telecommunication System Ltd., Mumbai, India). The patients were not disturbed during recordings. The ECG analogue signals were converted to digital signals using proprietary software and were stored in the computer in an American Standard Code for Information Interchange format for later offline analysis.

A baseline recording of ECG was made for $5 \mathrm{~min}$ before the start of anaesthesia. The patients received $10 \mathrm{ml} / \mathrm{kg}$ crystalloid intravenously before induction of anaesthesia. For inducing anaesthesia, propofol was infused into a separate venous line through a target-controlled infusion (TCI) pump (Orchestra Base Primea ${ }^{\circledR}$-Fresenius Kabi, France) using Schnider model. ${ }^{[12]}$ Initially, the Ce was set to $2 \mu \mathrm{g} / \mathrm{ml}$ (T1). Once the desired concentration was reached, the infusion was continued at the same rate for another $2 \mathrm{~min}$ to achieve a steady state equilibrium. ECG was then recorded for $5 \mathrm{~min}$ and stored as described above. After the recording, the Ce was increased to $4 \mu \mathrm{g} / \mathrm{ml}$ (T2). Once the desired concentration was achieved, the infusion was continued at the same rate for another 2 min to achieve a steady state, and the ECG was again recorded for $5 \mathrm{~min}$. The data collection ended at this time point, and the rest of the conduct of anaesthesia was left to the attending anaesthesiologist. During the study period, HR, respiratory rate and non-invasive blood pressure were recorded at the end and beginning of each 5 min ECG recordings. Throughout the procedure, $100 \%$ oxygen was administered to the patient through a mask, and if required, ventilation was assisted. The study protocol is outlined in the flow chart [Figure 1].

The digitised ECG recordings (sampling rate $512 \mathrm{~Hz}$ ) collected during the three time points were used to calculate the R-R interval from Pan Tompkins algorithm on a MATLAB platform. ${ }^{[13]}$ The calculated $\mathrm{R}-\mathrm{R}$ interval series was checked for any artefacts manually and if present, were removed. The R-R interval series were then entered into the Kubios software (http://uku.fi), open source software, for performing the HRV calculations in time domain, frequency domain and non-linear models. In our study, we intended to 
examine only short-term HRV changes in response to the anaesthetic administration. Majority of the earlier reports have studied short-term HRV using frequency domain variables, namely, low frequency (LF), high frequency $(\mathrm{HF})$ and $\mathrm{LF} / \mathrm{HF}$, and hence in this study, we evaluated the same parameters. ${ }^{[14]}$

\section{Statistical analysis}

All statistical tests were performed using Statistical Package for the Social Sciences (SPSS) software, Version 15 (SPSS Inc. Chicago, IL, USA). Continuous variables are represented as a mean and standard deviation. The demographic variables between the two groups were compared using $t$-test for continuous variables and Chi-square/Fisher's exact test for non-parametric data. In each group, baseline values of HRV parameters were compared with values at $2 \mu \mathrm{g} / \mathrm{ml}$ and with $4 \mu \mathrm{g} / \mathrm{ml}$ propofol Ce using repeated measures analysis of variance (rmANOVA). The HRV parameters of the study group were compared with those of the control group using rmANOVA test. Haemodynamic and HRV data obtained were adjusted for any demographic variable where there was difference between the study and control group. $P<0.05$ was considered statistically significant.

\section{RESULTS}

The craniotomy (study) group had 24 patients and the brachial plexus (control) group had 21 patients. The patients' demographics are depicted in Table 1. In the craniotomy group, 18 out of 24 patients had features suggestive of raised ICP (computed tomography of brain showing midline shift $>10 \mathrm{~mm}$, effaced basal cisterns). Patients in the control group were younger and had proportionately more males compared to the study group. The differences were statistically significant, and hence the results of all further analyses were adjusted for age and sex. The R-R artefacts in the patient dataset were $<5 \%$ and were manually removed before final analysis. Propofol consumption at different study time periods was comparable between two groups [Table 2].

\section{Haemodynamic changes}

At baseline, there was no difference in the heart rate and blood pressure between the two groups [Table 3]. Following propofol administration, there was a significant reduction in systolic and diastolic blood pressure in both the groups. HR increased significantly only in the brachial plexus group. When the haemodynamic

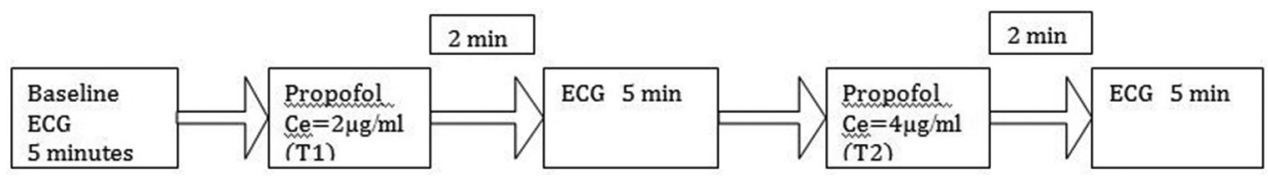

Figure 1: Flow chart showing the study protocol

Table 1: Demographic characteristics of patients

\begin{tabular}{lccc}
\hline Demographic variables & Craniotomy (study) group & Brachial plexus (control) group & $\boldsymbol{P}$ \\
\hline Number of patients & 24 & 21 & $28.3 \pm 7.3$ \\
Age (years), mean \pm SD & $35.8 \pm 8.3$ & $60.2 \pm 10.4$ & $0.003^{* *}$ \\
Weight $(\mathrm{kg})$, mean \pm SD & $59.1 \pm 8.5$ & $163.0 \pm 8.7$ & 0.36 \\
Height $(\mathrm{cm})$, mean \pm SD & $161.1 \pm 8.4$ & $20: 1$ & 0.55 \\
Male:female & $15: 9$ & $0.012^{*}$ \\
\hline
\end{tabular}

${ }^{* \star} P$ value significant at $<0.05,{ }^{*} P$ value significant at $<0.05$ (Fisher's exact test). $S D=$ Standard deviation

Table 2: Propofol consumption in two groups at different time points

\begin{tabular}{lccr}
\hline Stages of propofol infusion $(\mathrm{Ce}$ in $\mu \mathrm{g} / \mathrm{ml})$ & \multicolumn{2}{c}{ Dose of propofol consumed $(\mathrm{mg})$} & $P$ \\
\cline { 2 - 3 } & Craniotomy group & Brachial plexus group & \\
\hline $2 \mu \mathrm{g} / \mathrm{ml}$ & $35.1 \pm 2.6$ & $35.7 \pm 1.7$ & 0.801 \\
On achieving Ce: $2 \mu \mathrm{g} / \mathrm{ml}(\mathrm{T} 1)$ & $48.1 \pm 3.3$ & $49.4 \pm 4.4$ & 0.933 \\
At the beginning of ECG recordings (T1 + 2 min) & $82.4 \pm 7.1$ & $83.6 \pm 4.1$ & 0.863 \\
By the end of ECG recordings (T1+7 min) & & & 0.742 \\
$4 \mu \mathrm{g} / \mathrm{ml}$ & $124.9 \pm 9.9$ & $125.8 \pm 5.4$ & 0.459 \\
On achieving Ce: $4 \mu \mathrm{g} / \mathrm{ml}(\mathrm{T} 2)$ & $150.4 \pm 11.7$ & $151.9 \pm 7.1$ & 0.964 \\
At the beginning of ECG recordings (T2 + 2 min) & $215.8 \pm 17.8$ & $216.2 \pm 11.2$ & \\
By the end of ECG recording (T2+7 min) & & & \\
\hline
\end{tabular}

T1=Time when propofol Ce: $2 \mu \mathrm{g} / \mathrm{ml}, \mathrm{T} 2=$ Time where propofol Ce: $4 \mu \mathrm{g} / \mathrm{ml}$. ECG=Electrocardiogram, Ce=Effect site concentration 
changes were compared by rmANOVA at different time points, there was no significant difference between the craniotomy and the brachial plexus group [Table 3].

Heart rate variability parameters - comparison within groups and in-between groups

Between-group comparison of baseline heart rate variability parameters

Comparison of baseline HRV parameters between the two groups is depicted in Table 4 . In the time domain analysis, both mean RR and pNN50 were higher in the brachial plexus group although only pNN50 was statistically significant. In the frequency domain analysis, $\mathrm{LF}, \mathrm{HF}$ and total power were significantly higher in the brachial plexus group. However, sympathovagal balance measured in terms of LF/HF ratio was not statistically significant between the two groups.

\section{Brachial plexus group}

Changes in HRV parameters within the brachial plexus group at baseline and at different propofol Ce are shown in Table 5. With increasing propofol Ce, mean $R-R$ values decreased and were significant at $4 \mu \mathrm{g} / \mathrm{ml}$ when compared to baseline and at $2 \mu \mathrm{g} / \mathrm{ml}$. The sympathovagal balance as assessed by LF/HF ratio significantly increased at $4 \mu \mathrm{g} / \mathrm{ml}$ Ce and was due to low HF power. Total power increased from baseline to $2 \mu \mathrm{g} / \mathrm{ml}$ and then decreased at $4 \mu \mathrm{g} / \mathrm{ml}$.

\section{Craniotomy group}

Changes in HRV parameters within the craniotomy group at different propofol Ce are shown in Table 5. In this group of patients, with increasing Ce of propofol, mean R-R values increased, but those were significant only at $2 \mu \mathrm{g} / \mathrm{ml}$ propofol Ce. Compared to baseline

Table 3: Comparison of haemodynamic parameters at different time points

\begin{tabular}{|c|c|c|c|c|c|c|}
\hline \multirow{2}{*}{$\begin{array}{l}\text { Haemodynamic } \\
\text { parameters }\end{array}$} & \multicolumn{3}{|c|}{ Craniotomy group } & \multicolumn{3}{|c|}{ Brachial plexus group } \\
\hline & Baseline & Ce: $2 \mu \mathrm{g} / \mathrm{ml}$ & Ce: $4 \mu \mathrm{g} / \mathrm{ml}$ & Baseline & Ce: $2 \mu \mathrm{g} / \mathrm{ml}$ & Ce: $4 \mu \mathrm{g} / \mathrm{ml}$ \\
\hline $\mathrm{SBP}(\mathrm{mmHg})$ & $129.0 \pm 15.8$ & $119.0 \pm 13.2^{*}$ & $103.9 \pm 14.6^{\#, \$}$ & $137.4 \pm 16.7$ & $125.0 \pm 17.3^{*}$ & $104.4 \pm 13.9^{\#, \$}$ \\
\hline $\mathrm{DBP}(\mathrm{mmHg})$ & $81.0 \pm 10.9$ & $76.7 \pm 8.9^{*}$ & $66.4 \pm 10.7^{\#, \$}$ & $85.1 \pm 10.5$ & $76.6 \pm 10.4^{*}$ & $64.1 \pm 9.5^{\#, \$}$ \\
\hline HR (bpm) & $78.9 \pm 11.7$ & $75.8 \pm 13.5$ & $76.3 \pm 13.5$ & $71.3 \pm 15.2$ & $73.4 \pm 12.6$ & $77.4 \pm 11.2^{\#, \$}$ \\
\hline
\end{tabular}

${ }^{*} P<0.05$; baseline versus $2 \mu \mathrm{g} / \mathrm{ml},{ }^{\#} P<0.05$; baseline versus $4 \mu \mathrm{g} / \mathrm{ml},{ }^{\mathrm{s}} P<0.05 ; 2 \mu \mathrm{g} / \mathrm{ml}$ versus $4 \mu \mathrm{g} / \mathrm{ml}$. SBP=Systolic blood pressure, DBP=Diastolic blood pressure, $\mathrm{HR}=\mathrm{Heart}$ rate, $\mathrm{Ce}=\mathrm{Effect}$ site concentration

Table 4: Between-group comparison of baseline heart rate variability parameters

\begin{tabular}{|c|c|c|c|}
\hline HRV parameters (baseline) & Craniotomy group & Brachial plexus group & $P$ \\
\hline \multicolumn{4}{|l|}{ Time domain variables } \\
\hline Mean R-R (ms) & $778.7 \pm 120.8$ & $879.6 \pm 176.6$ & 0.091 \\
\hline pNN $50(\%)$ & $6.7 \pm 10.2$ & $22.3 \pm 17.0^{*}$ & 0.013 \\
\hline \multicolumn{4}{|l|}{ Frequency domain variables } \\
\hline Welch LF power $\left(\mathrm{ms}^{2}\right)$ & $262.5 \pm 233.3$ & $546.4 \pm 350.2^{*}$ & 0.028 \\
\hline Welch HF power $\left(\mathrm{ms}^{2}\right)$ & $217.3 \pm 222.3$ & $687.9 \pm 475.7^{*}$ & 0.001 \\
\hline $\mathrm{LF} / \mathrm{HF}$ & $2.2 \pm 2.2$ & $1.2 \pm 1.1$ & 0.197 \\
\hline Total power $\left(\mathrm{ms}^{2}\right)$ & $805.2 \pm 598.7$ & $2010.2 \pm 1132.9^{*}$ & 0.002 \\
\hline
\end{tabular}

${ }^{*} P<0.05$ significant. $\mathrm{HRV}=$ Heart rate variability, $\mathrm{LF}=$ Low frequency, $\mathrm{HF}=$ High frequency

Table 5: Between-group comparison of heart rate variability parameters at different propofol concentrations

\begin{tabular}{|c|c|c|c|c|c|c|c|c|}
\hline \multirow{2}{*}{$\begin{array}{l}\text { HRV } \\
\text { parameters }\end{array}$} & \multicolumn{3}{|c|}{ Craniotomy group } & \multicolumn{3}{|c|}{ Brachial plexus group } & \multirow{2}{*}{$\begin{array}{c}P \text { value } \\
\text { (between } \\
\text { groups) }\end{array}$} & \multirow[t]{2}{*}{ Interaction } \\
\hline & Baseline & Ce: $2 \mu \mathrm{g} / \mathrm{ml}$ & Ce: $4 \mu \mathrm{g} / \mathrm{ml}$ & Baseline & Ce: $2 \mu \mathrm{g} / \mathrm{ml}$ & Ce: $4 \mu \mathrm{g} / \mathrm{ml}$ & & \\
\hline Mean R-R (ms) & $778 \pm 120$ & $818 \pm 153^{\$}$ & $812 \pm 151$ & $879 \pm 176$ & $843 \pm 139$ & $793 \pm 117^{*, \#}$ & 0.53 & 0.505 \\
\hline LF power $\left(\mathrm{ms}^{2}\right)$ & $262 \pm 33$ & $209 \pm 216$ & $237 \pm 273$ & $546 \pm 350$ & $594 \pm 796$ & $610 \pm 916$ & 0.3 & 0.902 \\
\hline HF power $\left(\mathrm{ms}^{2}\right)$ & $217 \pm 222$ & $373 \pm 389^{\$}$ & $375 \pm 536$ & $687 \pm 475$ & $982 \pm 1416$ & $661 \pm 1191$ & 0.11 & 0.238 \\
\hline $\mathrm{LF} / \mathrm{HF}$ & $2.3 \pm 2.2$ & $1.1 \pm 1.5^{\$}$ & $1.4 \pm 1.5$ & $1.2 \pm 1.1$ & $1.2 \pm 1.1$ & $3.0 \pm 4.3^{\#}$ & 0.71 & 0.103 \\
\hline Total power $\left(\mathrm{ms}^{2}\right)$ & $805 \pm 598$ & $1072 \pm 1079$ & $1047 \pm 1162$ & $2010 \pm 1132$ & $2457 \pm 2997$ & $1962 \pm 2764$ & 0.22 & 0.677 \\
\hline
\end{tabular}

${ }^{*} P<0.05$ baseline versus propofol Ce: $2 \mu \mathrm{g} / \mathrm{ml}$; ${ }^{\#} P<0.05$ baseline versus propofol Ce: $4 \mu \mathrm{g} / \mathrm{ml}$ (within group comparison - brachial plexus), ${ }^{\$} P<0.05$ baseline versus propofol Ce: $2 \mu \mathrm{g} / \mathrm{ml}$ (within group comparison - craniotomy). HRV=Heart rate variability, LF=Low frequency, HF=High frequency, Ce=Effect site concentration 
values, the LF power decreased at $2 \mu \mathrm{g} / \mathrm{ml}$ propofol Ce and later increased at $4 \mu \mathrm{g} / \mathrm{ml}$ propofol Ce but did not reach baseline values. These changes were not significant. On the other hand, after propofol administration, HF power increased significantly from baseline. This increase was significant at $2 \mu \mathrm{g} / \mathrm{ml} \mathrm{Ce}$ and not at $4 \mu \mathrm{g} / \mathrm{ml} \mathrm{Ce}$. As a result, LF/HF ratio showed a decline with increasing Ce of propofol. Total power increased from baseline to $2 \mu \mathrm{g} / \mathrm{ml}$ and remained elevated at $4 \mu \mathrm{g} / \mathrm{ml}$.

\section{Between-group comparison of heart rate variability parameters at different propofol effect site concentration}

For the HRV parameters that were studied, neither differences nor interaction between the groups was significant.

\section{DISCUSSION}

The salient findings of our study are summarised as follows:

- Patients with intracranial tumours have low total, LF and HF power at baseline indicating impaired ANS function

- At baseline, LF/HF ratio was higher in intracranial tumour patients indicating high sympathetic activity due to raised ICP

- Administration of propofol resulted in the withdrawal of predominant frequency power of baseline ANS activity to begin with. This resulted in decreasing LF/HF values in intracranial tumour patients and increasing LF/HF values in brachial plexus group patients

- HRV variables in both the groups changed the same way in response to increasing Ce of propofol

- Propofol administration resulted in significant fall in blood pressure in both the groups, whereas heart rate increased significantly only in the control group, probably due to withdrawal of high baseline HF power.

HRV has been used extensively to study the ANS in various neurological disorders such as Alzheimer's disease, Parkinson's disease, traumatic brain injury and syncope. However, literature on ANS function in patients with intracranial tumour is scarce. One published report indicated that intracranial tumours can affect not only the level of consciousness but also pain and autonomic activity. ${ }^{[10]}$ Central nervous system-induced cardiac arrhythmias and palpitations have been reported to be associated with low-grade astrocytoma in the frontal lobe. ${ }^{[12,13]}$ Presence of impaired ANS function with associated impaired cerebral autoregulation can compromise CPP during surgery under general anaesthesia. Hence, the degree of autonomic dysfunction in patients undergoing intracranial procedures is of considerable interest to the neuroanaesthesiologists.

Patients in the craniotomy group had low total power as well as low LF and HF powers, when compared to controls, indicating disturbances in the ANS function. However, LF/HF was high at baseline indicating increased sympathovagal balance. This might be due to increased ICP in patients with intracranial tumours. On the contrary, at baseline, control group patients had low $\mathrm{LF} / \mathrm{HF}$ ratio indicating high parasympathetic activity.

In patients receiving spinal anaesthesia, pre-operative $\mathrm{LF} / \mathrm{HF}$ value $>2.5$ predicted hypotension. This is due to abrupt withdrawal of sympathetic activity following spinal anaesthesia. ${ }^{[4]}$ In our craniotomy patients, though $\mathrm{LF} / \mathrm{HF}$ values were high when compared to control group, the difference was not significant. Hence, fall in blood pressure was similar in both the groups.

Propofol administration resulted in the withdrawal of predominant component of ANS activity to begin with and later both divisions of ANS get suppressed at high doses of propofol. Hence, in craniotomy group, as LF was predominant, it got inhibited first resulting in decreasing $\mathrm{LF} / \mathrm{HF}$ ratio and vice versa for the control group. The fact that the interaction between the groups was not statistically significant on all HRV parameters suggests that the response to a given concentration of propofol is not grossly different between the two groups though there were significant baseline differences.

In patients undergoing surgery for brain tumours, Paisansathan et al. observed similar awake blood pressure, heart rate and $\mathrm{AF}$ as compared to neurosurgical controls. ${ }^{[14]}$ Our study differs from the above study in a few respects. They had included patients with spinal cord tumours as controls, which is not an ideal group for normal controls. Given the fact that spinal pathology can have a considerable impact on cardiac $\mathrm{AF}$, their study is representative of a comparison between two diseases known to have autonomic dysfunction. Symptoms related to increase in ICP were not recorded in their study. On the contrary, majority of our patients with supratentorial tumours had features suggestive of raised ICP. Kanaya et al. observed reduced HF with high LF/HF ratio in their patients (non-neurosurgical) following propofol administration which was significant at lowest BIS values. ${ }^{[5]}$ This finding was similar to ours, but BIS was not used in the current study.

$\mathrm{AF}$ in patients receiving anaesthesia could be a function of the depth of anaesthesia too; this was the basis of several earlier studies using HRV parameters to quantify the depth of anaesthesia. ${ }^{[15,16]}$ Therefore, it was necessary for us to report the HRV variables at comparable levels of anaesthesia. We chose to use TCI for this purpose, whereas 
there are other studies that used bispectral index. Yeganeh et al. showed a good correlation between TCI Ce and BIS value ${ }^{[17]}$ For delivery of intravenous anaesthetic, we chose the Schnider model during induction of anaesthesia, as it predicts the propofol effect site equilibration faster than the Marsh model. ${ }^{[18]}$ We chose $2 \mu \mathrm{g} / \mathrm{ml}$ and $4 \mu \mathrm{g} / \mathrm{ml}$ for our study as they are the most commonly used propofol effect site Ce used for inducing sedation and anaesthesia. ${ }^{[1]}$

HRV changes with age, sex, pre-existing disease, concomitant medications, diabetes and hypertension and liver and kidney diseases. None of the patients in both the study groups had any of the above-mentioned problems. However, the groups were significantly different with regard to age and sex. This was taken into consideration while performing the statistical analysis and the results were adjusted for age and sex.

One of the major limitations that we had in analysing and interpreting the results of the study was that the sample size could not be assessed a priori as there were no similar studies in the past in patients with brain tumours. For this reason, on some of the parameters, the statistical power was not adequate. However, the data from this study could form the basis for calculation of sample size for future studies to get better insights. The other limitation is that we studied HRV changes in craniotomy and control groups during propofol induction and found them to be similar between two groups in spite of baseline differences. Hence, whether these two groups would behave similar haemodynamically during patient positioning, episodes of blood loss and surgical stimulation need to be studied.

\section{CONCLUSION}

Patients with supratentorial tumours present with impaired cardiovascular ANS function. The severity of ANS impairment in relation to ICP needs to be studied. Propofol administration results in progressive inhibition of the ANS irrespective of the disease states. Future studies with other anaesthetics may show different results depending on their effects on the autonomic system. Studies similar to ours in patients with pre-existing autonomic disturbances caused by diabetes mellitus, hypertension, could be of practical relevance in neuroanaesthetic practice.

\section{Financial support and sponsorship}

The equipment used for ECG data collection was funded by Science and Engineering Research Board - Department of Science and Technology, India.

\section{Conflicts of interest}

There are no conflicts of interest.

\section{REFERENCES}

1. The autonomic nervous system and the adrenal medulla. In:
Guyton AC, Hall JE, editors. Textbook of Medical Physiology. $11^{\text {th }}$ ed. Philadelphia: Elsevier Saunders; 2006. p. 748-60.

2. Mazzeo AT, La Monaca E, Di Leo R, Vita G, Santamaria LB. Heart rate variability: A diagnostic and prognostic tool in anesthesia and intensive care. Acta Anaesthesiol Scand 2011;55:797-811.

3. Akselrod S, Gordon D, Ubel FA, Shannon DC, Berger AC, Cohen RJ. Power spectrum analysis of heart rate fluctuation: A quantitative probe of beat-to-beat cardiovascular control. Science 1981;213:220-2.

4. Hanss R, Bein B, Weseloh H, Bauer M, Cavus E, Steinfath M, et al. Heart rate variability predicts severe hypotension after spinal anesthesia. Anesthesiology 2006;104:537-45.

5. Kanaya N, Hirata N, Kurosawa S, Nakayama M, Namiki A. Differential effects of propofol and sevoflurane on heart rate variability. Anesthesiology 2003;98:34-40.

6. Lancon JA, Haines DE, Raila FA, Parent AD, Vedanarayanan VV. Expanding cyst of the septum pellucidum. Case report. J Neurosurg 1996;85:1127-34.

7. Yamour BJ, Sridharan MR, Rice JF, Flowers NC. Electrocardiographic changes in cerebrovascular hemorrhage. Am Heart J 1980;99:294-300.

8. Mowery NT, Norris PR, Riordan W, Jenkins JM, Williams AE, Morris JA Jr. Cardiac uncoupling and heart rate variability are associated with intracranial hypertension and mortality: A study of 145 trauma patients with continuous monitoring. J Trauma 2008;65:621-7.

9. Kahraman S, Dutton RP, Hu P, Stansbury L, Xiao Y, Stein DM, et al. Heart rate and pulse pressure variability are associated with intractable intracranial hypertension after severe traumatic brain injury. J Neurosurg Anesthesiol 2010;22:296-302.

10. Furgala A, Madroszkiewicz D, Madroszkiewicz E, Goscinski I, Kolasinska-Kloch W, Moskala M, et al. Autonomic system disturbances in patients with increased intracranial pressure caused by brain tumors evaluated by heart rate variability. Folia Med Cracov 2007;48:35-44.

11. Sharma D, Bithal PK, Dash HH, Chouhan RS, Sookplung P, Vavilala MS. Cerebral autoregulation and $\mathrm{CO} 2$ reactivity before and after elective supratentorial tumor resection. J Neurosurg Anesthesiol 2010;22:132-7.

12. Schnider TW, Minto CF, Shafer SL, Gambus PL, Andresen C, Goodale DB, et al. The influence of age on propofol pharmacodynamics. Anesthesiology 1999;90:1502-16.

13. Pan J, Tompkins WJ. A real-time QRS detection algorithm. IEEE Trans Biomed Eng 1985;32:230-6.

14. Paisansathan C, Hoffman WE, Lee M, Ananda RC, Wheeler P. Autonomic activity during desflurane anesthesia in patients with brain tumors. J Clin Monit Comput 2007;21:265-9.

15. Healy TE, Bellman MH, Pomfrett CJ. Respiratory sinus arrhythmia indicates light anaesthesia during caesarean section. Anesth Analg 1994;78:S156.

16. Pomfrett LJ, Barric JR, Healy TE. Respiratory sinus arrhythmia reflects surgical stimulation during light enflurane anaesthesia. Anesth Analg 1994;78:S334.

17. Yeganeh N, Roshani B, Almasi A, Jamshidi N. Correlation between bispectoral index and predicted effect-site concentration of propofol in different levels of target-controlled, propofol induced sedation in healthy volunteers. Arch Iran Med 2010;13:126-34.

18. Hollos L, Enraght-Moony N. Effect site targeted propofol infusion in clinical practice: Comparison to Diprifusor. Internet J Anesthesiol 2000;5:1-6. Available from: http://www. ispub.com/IJA/5/3/12168. [Last accessed on 2015 Jan 26].

19. Conway DH, Hasan SK, Simpson ME. Target-controlled propofol requirements at induction of anaesthesia: Effect of remifentanil and midazolam. Eur J Anaesthesiol 2002;19:580-4. 